\title{
THE ROLE OF ORGANIZATIONAL PROFESSIONALS IN THE CONSCIOUS EVOLUTION OF BUSINESS AND SOCIETY
}

\author{
SHERRYL STALINSKI \\ Aurora Now Foundation
}

\begin{abstract}
This paper explores the role of organizational professionals in the evolutionary development of business. Such professionals are currently defined in the fields of human resources development, organizational development and human performance improvement as executive and strategic coaches, training professionals and consultants. Their work seeks to improve the human systems on which organizational processes depend. This paper explores (a) areas of convergence and divergence among these fields; (b) how these professions might contribute to the conscious evolution of humane, sustainable and viable organizational cultures; and (c) the challenges and issues these professions must effectively address.
\end{abstract}

KEYWORDS: Organizational development, organizational culture, human resources development, coaching, training, and development.

As has been the case for nearly a century, our small blue planet remains in political turmoil, now with the added threat of terror, seemingly exponential entropy is now engulfing many economic systems, while environmental degradation threatens our future. In response, a global perspective addressing evolution of human and societal consciousness and culture seem to rightly demand the stage and spotlight of our collective awareness. Initiatives relating to fundamental human rights and dignity, democracy, and the protection of our precious wild places and valuable natural resources represent noble and courageous efforts. But transformation and human evolution at a global scale must manifest themselves comprehensively at all systemic levels. One environment with the potential to dramatically impact others on a global scale is the environment of business. From small home-based entrepreneurial microbusinesses (accounting for $60 \%$ of the new jobs in the United States between 1990-1996) (SBA 1998), to multinational corporations, private and publicly held enterprises impact almost every human on the planet, as well as our political, economic and natural systems.

And yet, emphasis on the business environment by professionals and scholars

Address correspondence to: Sherryl Stalinski, 1981 N. San Joaquín, Tucson, AZ 85743. E-mail: 
committed to global change can draw suspicion and questioning looks from many who see such emphasis as contrary to more altruistic endeavors. It is an unfortunate and misguided attitude against organizations that are critical to sustaining and transforming local and global economic processes.

5

\section{THE NEW NATURE OF HR DEVELOPMENT, ORGANIZATIONAL DEVELOPMENT, AND EMPLOYEE TRAINING}

During the industrial era, emphasis on bottom-line financial profit was used as a singular value against which organizational strategies were measured and evaluated. Even with the rise in popularity of such business management tools such as Total Quality Management, the ultimate criteria for success remained financial gain. Only as the new millennium opens are some market enterprises reevaluating the criteria by which success is gauged. Financial viability remains important, but in the aftermath of corporate scandals and bankruptcies, other values and criteria for evaluation are slowly gaining ground. In evaluating the effectiveness and performance of organizational culture, Daniel Dennison of the University of Michigan identifies six criteria in his Cultural Due Diligence assessment: Profit, sales growth, market share, development and innovation, quality, and employee satisfaction (in Juechter, Fisher, and Alford, 1998). Even emphasis on sales growth and market share are losing emphasis in favor of long-term organizational viability. Albrecht (2003) notes that financial indicators rarely predict an organization's lasting success, and that market dominance is, at best, a temporary and precarious achievement:

\begin{abstract}
A review of the past century of business performance indicates that the average life span of a Fortune 500 company is between forty and fifty years. The average life of all incorporated businesses is estimated at less than fifteen years. A business, once it navigates its survival phase, is not guaranteed eternal life. Firms that have survived 100,200 and 300 years or more show us that longevity is possible, but not assured. The legacy of the "bottom line," with its mantras of return on capital, is more closely correlated with short term survival than with a long and healthy life. We are coming to the understanding that enterprises that survive and thrive over the long run are not one-dimensional cash machines, but living, growing, evolving cultures of people and performance. In short, they are intelligent enterprises. (Albrecht, 2003, p. xii).
\end{abstract}

Instead of market domination and double-digit stock value increases, many business leaders and consultants are now looking to increase flexibility, adaptability, and the ability to change in changing environments; focusing more on long-term viability than on short term super-stardom. It seems to be a new priority with which investors will have to cope.

With new values emerging for employee satisfaction in healthy workplace environments coupled with emphasis on teamwork and shared commitment, the traditional professions of human resources and workplace training have evolved dramatically. Professionals once in charge of workplace skills training are now charged with a broader task of Human Performance Improvement (HPI). Soft-skills development, such as leadership training, relationship building, communication and dialogue skills, 
conflict management and customer appreciation, emphasize new foci on the human systems on which systemic organizational processes depend. Human Resources managers are now even expected to focus equally on employee development as benefits administration as on compliance and labor issues.

Out of the humanistic movements of the latter half of the Twentieth century emerged the field of practice known as Organizational Development. Professionals in this field work both internally and externally to the organization by focusing on individual human potential and the cultural health of the organizations in which they work. Even more recent has been the growth of the coaching profession, working usually one on one with employees to cope with executive leadership issues, career transition challenges, and life skills development. While some coaches have professional and educational backgrounds in psychology and behavioral health, coaching is different from therapy inasmuch as its emphasis on helping individuals realize their potential differs from a therapeutic focus on the diagnosis of, and remedial intervention in, dysfunctional characteristics. Most coaches provide specific knowledge of business and organizational strategy as well as support in the development of "people skills." Business consultants, aside from providing expertise or knowledge of specific operational functions, such as information technology systems, may also provide guidance in the implementation of programs designed to improve the collective performance of an organization. The Six-Sigma program which evolved out of the Total Quality Management movement, and Peter Senge's Fifth Discipline (1990) approach toward developing the learning organization, are two of the most popular approaches to increasing group performance in organizations. Even entrepreneurs and small business owners are finding value in participating in workshops emphasizing the building of relationships with internal and external stakeholders. Personality typing profiles and 'networking' workshops, often offered through local small business organizations, provide opportunities for even the smallest enterprises to understand and work with diverse human styles in effective ways.

Increasingly, the roles and responsibilities of these various workplace professions are shifting. Boundaries between HR and training, OD and coaching, HPI and development are fading. Each organization seems to have its own formula and objective for these roles, which can be very different depending on the organization with which one might be involved. But the effect is clear: professionals in all of these areas are engaged in work that impacts an organization's culture, as well as the effective participation of individuals within these cultures.

\section{NESTED SYSTEMS: ORGANIZATIONAL AND SOCIETAL CULTURE}

While it is common to visualize a model of diverse and interconnected human systems in terms of a nested holarchy in order to understand the influence and recursive impact each may have on the others in the system, such a model may still connote an inadequate hierarchy (individual-family-workplace-community-society). A more useful model using the concept of "syntegrity" within geometric polyhedra has been used effectively, most notably by Stafford Beer (1994). A model for integrating the eight dimensions of the Evolutionary Guidance System proposed by Banathy (1996) is offered by Stalinski (2002) through which individuals are chal- 


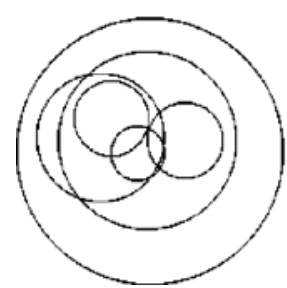

Nested systems

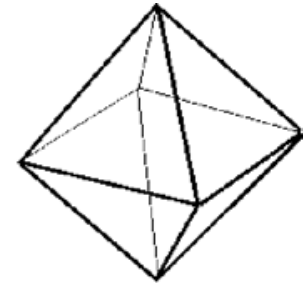

Polyhedra

Figure 1.

lenged to arrange these dimensions as an octahedron, examining the fit and influence of each dimension on the others. Judge (2003) suggests that

15 systems of knowledge organization are most significant in their inability to relate to each other or to handle polarities and paradoxes - from which their incommensurability partly stems. If the governance and development of society is subject to tensions from a variety of polarized perspectives, then knowledge organization would seem to need to be designed in the light of those polarities and paradoxes.

Geometric polyhedra are created by arranging the tension of polarities efficiently and effectively, creating structural strength and integrity. Christakis (1996, 2000) demonstrated the outcome of effective strategic dialogue when simply ranking multiple options by importance is followed by evaluating multiple options in sets of two for influence i.e., exploring whether polarities exist, creating either a push or pull influence within the set.

In using polyhedra to envision and model connected cultural systems, the opportunity exists to model the polarities of seemingly conflicting or competing cultures. Individual and group, economy and environment, government and family can be envisioned as diverse and necessary components of the global cultural systems complex, and the tension between them as necessary to the integrity and structural soundness of the meta-system.

In such a model, it is easy to envision the impact and influence that organizational cultures have on societal cultures, and vice versa; or the recursive influence of the individual on the multiple groups and cultures through which he or she moves every day: family, work, religion, economic and political spheres, ethnic culture, and community.

Morgan (1998) used a variety of examples to demonstrate the influence of workplace values in the home, and likewise how a larger national or societal culture can influence values in the workplace, noting these phenomena are clearly visible in both eastern and western cultures. Morgan is careful to point out that cultural systems are themselves complexes of many cultures, and the values associated with organizational roles (i.e., factory assembly line worker or executive); the values specific to ethnic, national or religious cultures; and individual values all affect and impact each other. 


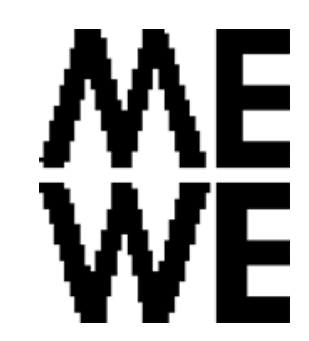

Figure 2. ME/WE

At the International Systems Institute, two teams on Evolutionary Learning Community and Healthy \& Authentic Community combined for two years to explore the nature of community, culture, stewardship and evolutionary learning (Stalinski, 2001). The combined teams created a model demonstrating the reflective and recursive relationship between an individual and their embedding culture

Envisioning the $\mathrm{ME} / \mathrm{WE}$ reflection in animated rotation, one can easily imagine how a single person can impact the cultures in which they live, and likewise, how their cultures affect them at the level of the individual. The ME/WE model is the simplest demonstration of the complimentary tension and influence between two apparent polarities. Envisioning a similar reflection between workplace cultures and societal cultures can raise considerably the value of the human and cultural development work performed by organizational professionals such as HPI trainers, coaches, OD consultants, and HR managers.

Engaging the most fundamental factor driving human behavior - values - organizational professionals empower employees, leaders and stakeholders to change their own behavior, and simultaneously model alternative and/or additional values within an organization's culture. The effects of transformation at the organizational level will have a strong impact on transformation at the global level.

\section{GUIDING ORGANIZATIONAL AND SOCIETAL CULTURAL EVOLUTION}

Banathy $(1996,2000)$ argues that cultural evolution took precedence over biological evolution in our species long ago. Ervin Laszlo writes:

Cultures are, in the final analysis, value-guided systems. [...] Values define cultural man's need for rationality, meaningfulness in emotional experience, richness of imagination and depth of faith. All cultures respond to such suprabiological values. But in what form they do so depends on the specific kind of values people happen to have (Laszlo, 1996, pp. 75-76).

Yet if culture is largely an unconscious process and an emergent phenomena of human systems (Schein, 1992; Morgan, 1998; Albrecht, 2003), how can organizational professionals truly empower individuals to guide their own human development as well as the evolution of their organizational cultures? Since values can be modified through conscious reflection, it is suggested here that culture can be guided through the conscious practice of behaviors that reflect changed values until such 
change manifests at the automatic and unconscious level, much the way that riding a bicycle is a conscious learning process until, through practice, it becomes automated at the tacit level.

The final critical question on the effort to guide cultural evolution is what values should be adopted and integrated into the process? In our diverse and complex world, suggesting any specific value system over any other would be counterproductive to the creation of healthy and sound cultural systems (and would be counterintuitive to holding polarities as a component of building strength). Instead, values which reflect the principles necessary for all open systems to grow and evolve, plus added value for the unique qualities of human systems, will enable us to embrace our diversity, accept complexity, strive for flexibility, acknowledge our need for meaning, and nurture our capacity for innovation and creativity.

\section{REFERENCES}

Albrecht, K. 2003. The power of minds at work: Organizational intelligence in action. New York: American Management Association (AMACOM).

Banathy, B. H. 1996. Designing social systems in a changing world. New York: Plenum.

Banathy, B. H. 2000. Guided evolution of society: A systems view. New York: Kluwer Academic/Plenum.

Beer, S. 1994. Beyond dispute: The invention of team syntegrity. New York: Wiley

Christakis, A. 1996. A people science: The CogniScope system approach. Systems 1(1): 1619.

Christakis, A. 2001. The dialogue game. Paoli, PA: CWA Ltd.

Judge, A. 2003. Evoking Authenticity through polyhedral global configuration of local paradoxes. Retrieved 5/16/03 from $<$ http://laetusinpraesens.org/docs00s/authen.php $>$.

Juechter, Fisher, Alford. 1998. Five conditions for high performance cultures Training \& Development, Alexandria, VA: ASTD.

Laszlo, E. 1996. The systems view of the world. Cresskill, NJ: Hampton Press.

Morgan, G. 1998. Images of organization. San Francisco: Berrett-Koehler.

30 Schein, E. 1992. Organizational culture and leadership. 2nd Edition. San Francisco: JosseyBass.

Senge, P. 1990 The fifth discipline. New York: Doubleday.

Stalinski, S. 2001. Creating futures: A systems view of transformation for our organizations, communities and world. Tucson, AZ: Aurora Now Foundation.

35 Stalinski, S. 2002 The Integrity Game. Tucson, AZ: Aurora Now Foundation. of small firms. Washington, DC: U.S. Small Business Administration Office of Advocacy. 